THURSDAY, FEBRUARY 19, 1874

\section{PHYSIOLOGY AT CAMBRIDGE}

W

$\mathrm{E}$ are not of those who believe that the quality of the scientific work produced by any country as a whole, is dependent to any great extent on the facilities afforded for special study, though the amount yielded in any special direction varies directly as the opportunities and encouragement which are offered. All experience goes to show that the ability of the individual is a constant quantity, and that whatever direction his mind takes, as the result of the circumstances in which he is situated, he is sure to rise to a certain standard of excellence in the quality of his productions, and no higher ; in other words, the same facts put before two men of different mental powers will be employed in producing results of different quality, dependent on those powers. The backward state of physiology, and it may be said, of biology generally in comparison with the more exact sciences, has recently become so conspicuous, that attempts are being made by many of the leading scientific men to attract into these comparatively untrodden paths some of those able minds which would otherwise have devoted their best energies to the mastery and furthe $\boldsymbol{r}$ elucidation of points in a subject such as mathematics which may be almost said to have reached the limit of human mental power, as far as the methods at present at its disposal are concerned. In biology and physiology, however, the case is very different; their students may be said to be suffering from a glut of facts and disconnected minor theories, which want the assistance of some master minds to weed and connect them, so that the road may be made more easy for other less gifted workers. That such is the case is rendered evident by the undecided and tentative way in which most biological problems are on all sides discussed, Opinions the most opposite are held on fundamental points by partisans of different schools, and discussion becomes more a question of which side can be most subtle in its language or most dogmatic in its statements, rather than which is the true exponent of the subject under consideration. In such cases the precise statement of the problem by a master-mind would set the question at rest once and for all.

There are, however, many difficulties in the way of getting men suitable for this higher work, and for more than one reason. One of these is that there are very few who can be made to undertake the thorough training in more than a single subject, that is necessary for it. A student of ability at the University of Cambridge, for instance, takes up mathematics, and too soon finds that he has every reason to expect considerable pecuniary reward if he devotes the whole of his period of studentship to working for his tripos; he cannot but devote the whole of his time to the single subject, for otherwise those of equal powers who did so would beat him in the race and prevent his appearing in the tripos list in that position which insures him a fellowship, and therefore a competency. He keeps to his subject and reaps the reward; but by that time other duties, generally of a social nature, together with the narrowing effect of his one-sided education, have removed all his inclination to strike out a fresh line of thought, and he commences the routine of life, acquiring by every-day experience those facts which so many others of equal ability have learned before, and which he cannot therefore turn to any good account. The great defect of the Cambridge mathematical tripos is that it is too ultimate, and too complete in itself. The day on which the list comes out is that on which most think that mathematics has done as muck good to them as it can do, and on that day most throw over for ever that genuine method of working which has occupied so much of their time and thought during the three or more previous years, never to return to it.

Things being so, all must have felt intense satisfaction at the establishment at last of laboratories in Cambridge, such as that for Practical Physiology by Trinity College, under the able superintendence of Dr. Michael Foster, and that for Practical Physics by the Chancellor, under Prof. ClerkMaxwell, whose return to Cambridge has itself been a great stimulus to the advance of the subject in which he so greatly and so justly shines.

The first instalment of original papers from the former of these newly-founded institutions has recently been published. From the manner in which the researches have been conducted, from the thoroughly scientific and careful method of work adopted, the great discretion and experience of the ${ }_{j}$ Professors, as well as the excellent quality of the minds, with the assistance of which he has to deal, are evident. No teacher can help having a feeling of satisfaction at such work as that of Mr. Balfour and Mr. Liversidge, which shows signs of excellent mental training as well as a thorough love of the subject. Dr. Foster's standard is evidently a high one, and from the papers before us it is certain that on future occasions only thorough work, based on well-verified facts, arrived at by the most approved modern methods, and checked by the researches of previous authors, are to be expected from his laboratory.

Besides the papers on the development of the blastoderm and blood-vessels of the chick, and on the amyloid ferment of the pancreas, by the two above-mentioned authors, Dr. Martin gives some short notes on the structure of the olfactory mucous membrane in connection with the observations of Max Schultze and Exner. Mr. Dew. Smith records the results of observations-made with the assistance of that beautiful instrument the pendulum myographion-on double nerve stimulation, or the simultaneous stimulation, by two pairs of electrodes, of a single nerve, with well-marked and very instructive results. Mr. Yule also has a paper on the mechanism of opening and closing the Eustachian tube, in which, besides clearing up some points connected with their physiological function, he throws fresh light on the correct anatomy of their pharyngeal orifices.

In one of the papers, that by Dr. Foster himself, which is referred to by Mr. Lewes in this Journal (NATURE, vol. ix. p. 83), Mr. T. O. Harding, senior wrangler in 1872, is mentioned as one of those who have bsen working in the laboratory. This is a most promising sign; for, as previously remarked, nothing is more wanted than the assistance of such men, in order to show the bearing and value of the various facts laid stress on by pure physiologists. We hope that 
Dr. Foster will be successful in attracting other advanced mathematicians to the study of his subject; and better still, that he will be able to persuade those who are in the beginning of their undergraduate mathematical education to devote some of their spare time-quite a recreation as it would be-to learning the first principles and the methods of physiological research, under his able supervision.

Truly Dr. Foster and Dr. Clerk-Maxwell have a noble work before them, and we may hope that by their example and precept Cambridge may after a lapse of thirty or forty years, in the matter of physical and physiological research, be on a level with a second-rate German University.

\section{ATHENIAN TEXT-BOOKS OF SCIENCE}

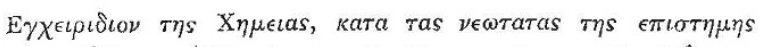

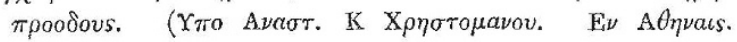
1871.)

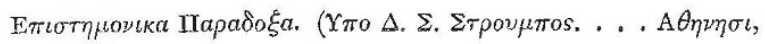
I 864.)

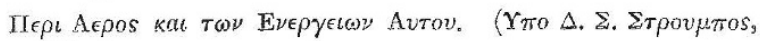
1869.)

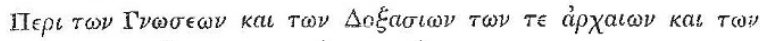

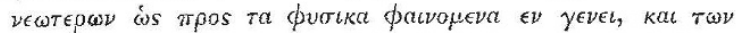

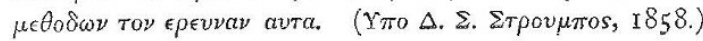

7 HE University of Athens has existed for no more than thirty-seven years. Two of its four Faculties, -the Faculty of Medicine and the Faculty of Philosophy, require a knowledge of nätural philosophy and chemistry. It is difficult to understand how these subjects could have been taught at first, for the students by no means often understand French, and no Greek books on science then existed. No doubt the professors taught as Plato and Aristotle taught; and the note-book of the student had to be his text-book. But matters have changed since then: the demand for text-books in Greek has caused them to appear; slowly indeed, for we have seen but few books on science, but we may hope that the original textbooks which are now beginning to appear are the first of a continuous series. Do not let it be imagined that the works whose titles are given above are the only works on science we could find in all Athens. There is a big book on Physics by M. Damaskenos, who has also written on trigonometry and meteorology ; there are various memoirs by $M$. Stroumpos on the refraction of light; on the internal constitution of flame; on the fundamental principles of hydrostatics, \&c. The University is tolerably well supplied with physical and chemical apparatus, and in good time, we hope, some good student-work will be done there.

Many of the professors have studied in Paris, and we see evidence in the text-books of French science and of French thought. Prof. Chrestomanos appears, however, in the compilation of his Chemistry, to have consulted most of the recent books and memoirs. We are glad to see Canizzaro often quoted as an authority. The work does not present any specially noteworthy features, but it is sound and eminently clear. The phraseology is at times somewhat strange to a western student; thus we do not em- ploy such words as "Physiography" and "Phutology." ... After some prefatory remarks concerning the division of the sciences, we have a few pages given to the history of chemistry. The period of Alchemy is wrongly stated to extend from 400 to 1500 A.D. Then Iatrochemistry from 1500 to 1650 ; Phlogistic chemistry from 1650 to 1783 ; the new chemistry of Lavoisier and Davy, and so on to the chemistry of Kekulé and Canizzaro. This is followed by a short account of physical chemistry ; then an account of crystallography with good figures of crystals. Although many of the names of our elements are derived from the Greek, the table of elements looks rather puzzling : lead is of course $\mu$ ó $\lambda v \beta \delta o s$, while molyb-

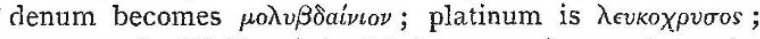
tungsten (or Wolfram) is $\beta \circ \lambda \phi \rho а \mu l o \nu$; nitrogen is at the beginning of the alphabetical list; copper near the end. Again, as to compounds the names of the oxides of

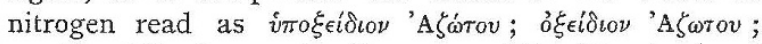

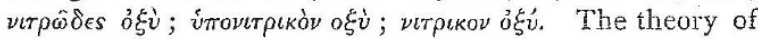
atomicities is well developed : niobium and tantalum are the only pentatomic elements; while molybdenum and tungsten are the only hexads. The peculiar atomicities of nitrogen and iron are not noticed. The building up of compounds on the type respectively of one, two, and three molecules of water is fully discussed (koopoy is the term used in place of our low-Latin molecula). Full tables of grouped elements appear; and the naming of compounds is considered. After this considerable and important introduction the work begins with hydrogen in the usual manner, and the account of the other element follows in due course.

The "Scientific Paradoxes" of Prof. Stroumpos is a volume of essays on physics and physiology ; including magnetism, electricity, illusions, alchemy. Here too we find paradoxes of another kind; would Mr. Glaisher recognise his name as of $\Gamma \lambda a u \sigma \chi \in p_{0}$, or $\mathrm{Mr}$. Coxwell as

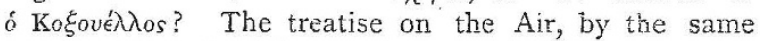
author, is a tolerably complete treatise on pneumatics, iliustrated by very crude, but original and sufficient woodcuts. The discourse on the history of Science is very interesting, and full of excerpts from Plato, Aristotle, and other ancient writers. For them we think Prof. Stroumpos has claimed too much; we cannot with any degree of certainty assert that Aristotie discovered that the air possesses weight. His experiment at the outset is altogether faulty, for he tells us that an inflated skin (o $\pi \epsilon \phi \nu \sigma \eta \mu \dot{\epsilon} \nu$ s ácòs) weighs more when filled with air than when empty, that is, not inflated. This of course we know from the law of Archimedes is false; a bladder full of air weighed in air can weigh no more than the uninflated bladder.

These works constitute the commencement of Athenian science. The city, while its art, and literature, and philosophy, have unhappily long passed their culminating point, is more scientific than it has ever been before. Not far from the place in which the Peripatetic made his experiment with a crude statera and an empty wine skin with Theophrastus as demonstrator, Stroumpos now weighs his really vacuous vessel, and Chrestomanos explodes oxygen and hydrogen. Thirty years of science in a remote city, out of the highways of European intelligence, cannot effect much ; but we hope in the course of the century original workers will multiply in Athens, and as much will be done to promote chemistry and physics, 